\title{
Does the edge effect impact on the measure of spatial accessibility to healthcare providers?
}

Fei Gao ${ }^{1,3,5^{*}}$, Wahida Kihal ${ }^{2}$, Nolwenn Le Meur ${ }^{1,3,5}$, Marc Souris ${ }^{4}$ and Séverine Deguen ${ }^{1,6}$

\begin{abstract}
Background: Spatial accessibility indices are increasingly applied when investigating inequalities in health. Although most studies are making mentions of potential errors caused by the edge effect, many acknowledge having neglected to consider this concern by establishing spatial analyses within a finite region, settling for hypothesizing that accessibility to facilities will be under-reported. Our study seeks to assess the effect of edge on the accuracy of defining healthcare provider access by comparing healthcare provider accessibility accounting or not for the edge effect, in a real-world application.
\end{abstract}

Methods: This study was carried out in the department of Nord, France. The statistical unit we use is the French census block known as 'IRIS' (Ilot Regroupé pour I'Information Statistique), defined by the National Institute of Statistics and Economic Studies. The geographical accessibility indicator used is the "Index of Spatial Accessibility" (ISA), based on the E2SFCA algorithm. We calculated ISA for the pregnant women population by selecting three types of healthcare providers: general practitioners, gynecologists and midwives. We compared ISA variation when accounting or not edge effect in urban and rural zones. The GIS method was then employed to determine global and local autocorrelation. Lastly, we compared the relationship between socioeconomic distress index and ISA, when accounting or not for the edge effect, to fully evaluate its impact.

Results: The results revealed that on average ISA when offer and demand beyond the boundary were included is slightly below ISA when not accounting for the edge effect, and we found that the IRIS value was more likely to deteriorate than improve. Moreover, edge effect impact can vary widely by health provider type. There is greater variability within the rural IRIS group than within the urban IRIS group. We found a positive correlation between socioeconomic distress variables and composite ISA. Spatial analysis results (such as Moran's spatial autocorrelation index and local indicators of spatial autocorrelation) are not really impacted.

Conclusion: Our research has revealed minor accessibility variation when edge effect has been considered in a French context. No general statement can be set up because intensity of impact varies according to healthcare provider type, territorial organization and methodology used to measure the accessibility to healthcare. Additional researches are required in order to distinguish what findings are specific to a territory and others common to different countries. It constitute a promising direction to determine more precisely healthcare shortage areas and then to fight against social health inequalities.

Keywords: Edge effect, Potential spatial accessibility of healthcare professionals, E2SFCA algorithm, Geographic information systems, Spatial analyses, Pregnant women

\footnotetext{
*Correspondence: fei.gao@ehesp.fr

${ }^{5}$ Department of Quantitative Methods for Public Health, EHESP School

of Public Health, Avenue du Professeur Léon Bernard, 35043 Rennes,

France

Full list of author information is available at the end of the article
} 


\section{Background}

Equitable distribution of health resources is a key priority for health professionals and policy makers worldwide; reducing health inequalities has long been of concern to community and public health planners [1-4]. Access to healthcare, as one potential driver of health inequalities, is at the heart of public health policy and is internationally recognized as a key goal in meeting the essential health needs of individuals [5-8].

Access to healthcare varies across space due to the uneven distribution of both healthcare providers and consumers, and the impact of geographical location on health is increasingly being examined. Various studies in Europe (including France) have shown unequal distribution of health service resources [9]. With heightened interest in residential neighborhood the characteristics that could influence health behaviors and outcomes, spatial accessibility and availability indices are being used in epidemiological studies more and more [10-15]. As a measure for determining those areas having inadequate levels of health service provision, spatial accessibility of health services refers to relative access to health services in a given location, which is influenced primarily by travel distance (or travel time) and the spatial distribution of health service providers and consumers [16-18]. Most studies examining the geographical accessibility of healthcare and health-related services have suggested a growing range of indices, including Physician Population Ratio, nearest distance, shortest time, cumulative opportunity and the gravity model [5, 19-26]. Recent methodological developments in this field have emerged in international research, including Enhanced 2-Step Floating Catchment Area method (E2SFCA) [27], which provides a summary measure of two important and related components of access: volume of services provided relative to population size, and proximity of services provided relative to population location.

In addition, one methodological limitation often mentioned in research considering accessibility concerns the fact that studies failed to include behavior outside the study area [17, 28-39]. Known as the edge effect, it is central to this paper. Edge effect occurs "when the study area is defined by a border which does not actually prevent travel across the border" [40] and people are free to travel beyond that border to receive healthcare goods and services. Arbitrary administrative boundaries (such as census tracts or block groups) are often used without consideration that resources beyond a given boundary are likely to affect behaviors within a given spatial unit [35]. This means that any geographic distribution or spatial interaction occurring within the spatial unit may extend beyond its boundaries [30]. More precisely, edge effects manifest when the boundaries of the study area affect a given spatial measurement and lead to the distortion of estimates [35, 41]. Interestingly, although most studies do mention potential errors caused by the edge effect, many acknowledge their mistake in neglecting to consider this in the spatial analyses they have undertaken within a finite region [42]. Because this can result in areas close to the boundary being classified as having poor geographic access even though they may in fact be proximate to resources across the boundary, many research projects have hypothesized that failure to accounting for edge effect will lead to considerable biases [34-37], even under-reporting $[17,28,29,31,43]$ of accessibility to facilities.

Although edge effect is a well-documented phenomenon, researches choosing this issue as the main subject used for most of the time distance/travel time measure $[34,35]$, or availability measures such cumulative index [28, 34, 35, 38, 43]. Focusing on E2SFCA method, the edge effect is frequently observed in studies measuring the spatial accessibility to healthcare providers. More and more studies have corrected for edge effects [32, 33]. However, to the best of our knowledge, very few studies based on E2SFCA have focused on edge effect in a realworld application with a view to quantifying its effect on the accuracy of defining health service access.

In this context, our study compares health service accessibility when accounting or not for the edge effect, taking into account that patients may overcome geographical boundaries, choosing to consult health professionals in neighboring departments. The geographical accessibility indicator used to quantify spatial accessibility is the Index of spatial accessibility (ISA), based on the E2SFCA algorithm. ISA was previously developed by our team for the pregnant women population, focusing on the three types of healthcare professionals (GP, midwife and gynecologist) involved during the pregnancy [44]. Conducted in the department of Nord at French census block spatial scale, our study aimed to quantify edge effect bias using the ISA index, and investigate the impact on spatial analysis results.

Besides, it is well documented that levels of accessibility and utilization of healthcare are related with socio-economic distress level and geographical factors [45-48]. Consequently, in our study, we investigated the urban-rural disparity of ISA as well as the relationship of ISA with socioeconomic distress variables, both when offer and demand beyond the area of study are excluded or included. The underlying questions are: Would the association between socioeconomic factor and accessibility be biased by ignoring spatial interaction occurring between the spatial unit and its neighborhood? Would the difference of accessibly between urban/rural areas be accentuated? 


\section{Methods}

\section{Data and measures}

Study setting and statistical unit

This study was carried out in the department of Nord, located in the north of France, close to the Belgian border. Analysis was conducted at French census block level (known as IRIS: “Ilots Regroupés pour l'Information Statistique") defined by the National Institute of Statistics and Economic Studies (INSEE) [49], which is the smallest infra-urban level for which census data is available. There are 1346 IRIS in the department of Nord.

\section{Neighborhood characteristics}

Two types of neighborhood characteristic were used at census-block level:

(i) Degree of urbanization (rural/urban) Each IRIS was classified as urban or rural according to the classification established by the national census bureau. These data are openly available from (https://www. insee.fr/fr/information/2017499) [49].

(ii) Level of socioeconomic distress According to previous work on social health inequality [50], we selected five variables from the 2006 French census (https://www.insee.fr/fr/information/2017499) [49] to characterize the neighborhood socioeconomic level: low level of educational attainment, women's unemployment rate, single parent families, nonhomeowner, and insecure employment situation (see variables definition in "Appendix I").

\section{Health professionals}

The postal addresses of GPs, midwives and gynecologists were obtained from the French state health insurance website (http://www.ameli-sante.fr) in 2014 [51]. To assess the edge effect, we considered the health professional offer both within and outside of the department of Nord. Service providers were represented by their geocoded professional addresses (latitude, longitude), obtained through Batch Geocoder (http://dehaese.free.fr/Gmaps/ testGeocoder.htm). Eight general practitioners and one obstetrical gynecologist were excluded from the analysis due to low quality of professional postal addresses. No georeferencing quality difference was detected between adjacent department and Nord Department. Further methodological details are available elsewhere [44].

\section{Index of spatial accessibility (ISA)}

ISA is an indicator which measures healthcare service accessibility.

The ISA is based on the E2SFCA method, a method which maintains the advantages of a gravity model while being easier to interpret, since it represents a derived form of a Physician Population Ratio. As the name suggests, two steps must be performed:

Step 1 For each provider in location $k$, look up all population locations of IRIS $i$ within a catchment, and within a predefined distance $d_{i k}$ from location $\mathrm{k}$. A distance decay function is applied within a catchment. $w\left(d_{i k}\right)$ is the weight quantifying travel time between IRIS $i$ and healthcare provider $k$. Sum up all population sizes $(\mathrm{Pi})$ within that catchment area to compute the provider-to-population ratio $\left(R_{k}\right)$ :

$$
R_{k}=\frac{1}{\sum_{d_{j k}<d_{\max }} P_{i} * w\left(d_{i k}\right)}
$$

Step 2 For each population location $i$, look up all provider locations $k$ that are within the catchment from location $i$. Sum up all $R_{k}$ for the catchment area to calculate the Index of spatial accessibility $\left(I S A_{i}\right)$ at location $i$ :

$$
I S A_{i}=\sum_{\mathrm{d}_{\mathrm{ij}} \leq \mathrm{d}_{\max }} w\left(d_{i j}\right) R_{k}
$$

ISA takes into account:

(i) The latitude and longitude of each healthcare professional.

(ii) The centroids of residential buildings for each IRIS (Residential buildings came from BD TOPO ${ }^{\circledR}$ and was provided by the Institut National de l'Information Géographique et Forestière (French National Geographic Institute) [52]). And

(iii) Car travel time, calculated by Google Maps. We used the FILENAME statement and the URL access method within SAS to access Google Maps, and extracted both the driving time and distance each time the site was accessed $[44,53]$.

We estimated an ISA for GPs, gynecologists and midwives, separately. A composite ISA relying on principal component analysis was also calculated, describing overall accessibility of the three types of healthcare professionals. Further details of the method developed for ISA estimation are given in [44].

\section{Decay function and travel time threshold}

We defined the time threshold according to figures already published by the French Institute for research and information in health economics for general practitioners [54]: 
- less than 5 min' travel: fully access to healthcare providers $(w=1)$

- more than 15 min' travel: no access to healthcare providers $(w=0)$.

- between 5 and 15 min: partial access to healthcare providers ( $w$ is defined by a continuous decay function [Eq. (3)] with the weighting factor equal to 1.5 [55])

$$
w=\frac{(15-d)}{(15-5)} e^{1.5}
$$

We based the threshold of the two other healthcare professionals on general practitioners' results: the nearest travel time to general practitioner is lower than $5 \mathrm{~min}$ and between 5 and $15 \mathrm{~min}$ for 88 and 12\% of the population, respectively; we used these proportions to define the threshold for two other health professionals: 15 and $34 \mathrm{~min}$ for gynecologists and 17 and $34 \mathrm{~min}$ for midwives.

Figure 1 provides an illustration of the impact of including offers and demands outside the study area defining what we call the "patient area" or catchment. This illustration deals with gynecologists only for the IRIS named "Fournes-en-Weppes" (IRIS no. 592500 000), with keys for reading.

Keys for reading Fig. 1 and fully understanding the principle of edge effect:

- Figure 1a-study area without consideration of offer and demand beyond the boundary

- All 218 gynecologists are represented by dark purple dots. The IRIS "Fournes-en-Weppes" is highlighted in fuchsia and circled in orange. We count 146 gynecologists accessible by car within 34 min of Fournesen-Weppes, within the study area. The 1201 IRIS are highlighted in purple forms the "patient area" of the 146 gynecologists (circled in orange). Figure $1 \mathrm{~b}-$ study area with consideration of offer and demand beyond the boundary

With edge effect, the residents of Fournes-en-Weppes could reach 181 gynecologists (an additional 35 from outside) within 34 min by car. However, they must share these with 2203 IRIS (1001 IRIS from outside). "Patient area" IRIS are colored purple.

\section{GIS methods}

We began by quantifying a global ISA spatial autocorrelation, separately with, and without, consideration of offer and demand beyond the department of Nord, based on Moran's I statistic (calculated by means of the distance matrix) [56-58]. Spatial autocorrelation can be defined as the coincidence of value similarity and locational similarity [59]. Positive spatial autocorrelation therefore exists where the high or low values of a random variable tend to be spatially clustered, with negative spatial autocorrelation existing where geographical areas tend to be surrounded by neighbors having highly dissimilar values. The values of the Moran's I statistic range from -1 to +1 .

Next, a Local Indicator of Spatial Autocorrelation (LISA) was applied. More precisely, Moran's diagram was produced in order to reveal the types of spatial relationship between a geographic unit and its neighboring area.

Four types of LISA can be detected: High-High $(\mathrm{HH})$ : high level of ISA in both a given IRIS and in its neighbors and Low-Low (LL): low level of ISA in both a given IRIS and in its neighbors, characterizing a positive association; High-Low (HL): high level of ISA in a given IRIS, whereas its neighbors have a low level of ISA and LowHigh (LH): low level of ISA in a given IRIS, whereas its neighbors have high level of ISA, characterizing a negative association.

\section{Statistical analysis Classification}

In order to analyze ISA variations when offer and demand outside are included, the 1346 IRIS making up the Nord department are divided into three classes, named improved, unchanged and deteriorated. These classes were constructed according to the results obtained using the simple linear regression model, where $\mathrm{Y}$ and $\mathrm{X}$ correspond to the ISA estimated with and without taking into account offer and demand across the boundary, respectively (see "Appendix II").

\section{Statistical associations}

ISA's composite values when offer and demand beyond the boundary were then cross-referenced with the individual variables of socioeconomic distress mentioned in the data section. The statistical significance of the relation was tested using a simple linear regression where $Y$ and $\mathrm{X}$ were the ISA index and one of the socioeconomic variables, respectively. The $\alpha$-risk was set at $5 \%$.

\section{Strategy and the statistical analysis plan}

Preliminary work was carried out to study ISA variation when offer and demand outside are excluded or included, and the spatial distribution of this variation. To quantify overall and local autocorrelation of ISA in the two cases, the GIS method was then applied. Following this, we analyzed the ISA variation for urban and rural zones, separately. Finally, we compared the relationship between the socioeconomic distress variable and ISA, to find out whether there is an impact when studying the association, 


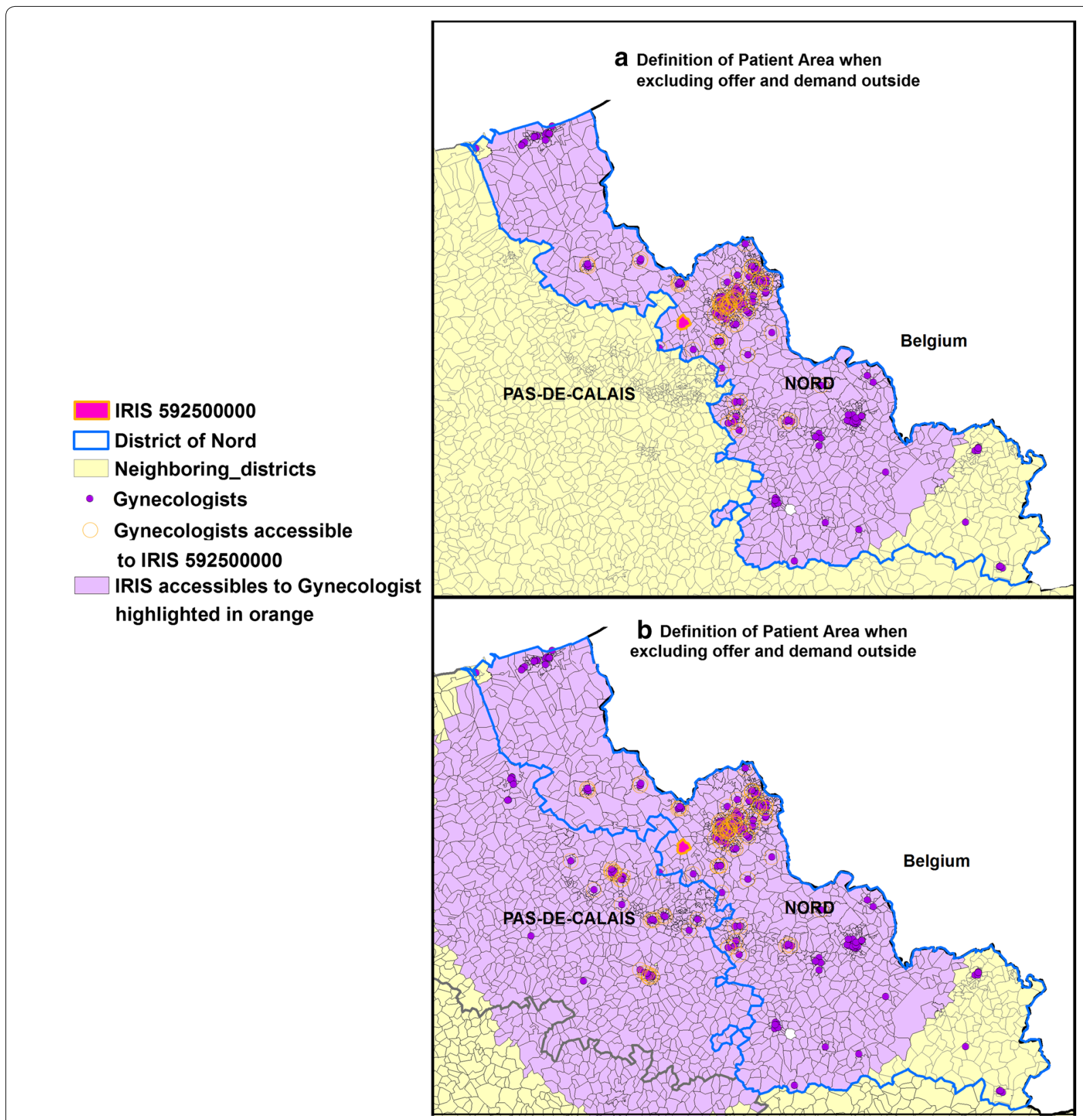

Fig. 1 Definition of "patient area" when including and excluding offer and demand outside. Focus on the IRIS named "Fournes-en-Weppes"- (IRIS no. 592500 000), the Nord department are circled in blue, whereas neighboring IRIS from the three departments of Somme, Aisne and Pas-de-Calais are yellow. a) without consideration of offer and demand beyond the boundary; b) with consideration of offer and demand beyond the boundary

both when excluding and including healthcare offer and demand outside the area of study, to account for a deficiency in analysis termed the "edge effect".

\section{Results}

Descriptive results

When excluding healthcare providers outside the department boundary, we geolocalized 2590 GPs, 143 midwives and 218 gynecologists. In order to include offer and demand beyond outside, we added 493 GPs, 60 midwives and 78 gynecologists from the neighboring area who were capable of providing services to those residing in the department of Nord. Ignoring the offer beyond the department led to an $18 \%$ decrease in the total number of health professionals potentially available; this decrease reaches $30 \%$ when focusing on midwives (Table 1 ). 
Table 1 Number of health professionals by medical specialty

\begin{tabular}{|c|c|c|c|c|c|c|c|}
\hline \multirow{2}{*}{$\begin{array}{l}\text { Medical special- } \\
\text { ity of health } \\
\text { professional }\end{array}$} & \multicolumn{3}{|c|}{ Number of healthcare providers } & \multicolumn{4}{|c|}{ Number of IRIS of "patient area" } \\
\hline & $\begin{array}{l}\text { Department } \\
\text { of Nord }\end{array}$ & $\begin{array}{l}\text { Neighboring } \\
\text { IRIS }\end{array}$ & $\%$ increase & $\begin{array}{l}\text { Department } \\
\text { of Nord }\end{array}$ & $\begin{array}{l}\text { Average popula- } \\
\text { tion }\end{array}$ & $\begin{array}{l}\text { Neighboring } \\
\text { IRIS }\end{array}$ & $\begin{array}{l}\text { Average popu- } \\
\text { lation }\end{array}$ \\
\hline GPs & 2590 & 493 & 16 & 1346 & 1905 & 1362 & 1076 \\
\hline Midwives & 143 & 60 & 30 & 1346 & 386 & 2425 & 187 \\
\hline Gynecologists & 218 & 78 & 26 & 1346 & 986 & 2583 & 484 \\
\hline Total & 2951 & 631 & 18 & - & - & - & - \\
\hline
\end{tabular}

After calculation of travel time via Google Maps, when including offer and demand beyond the boundary, "patient area" is not restricted to the 1346 IRIS of the department of Nord. In all, 1362, 2425 and 2583 IRIS in the departments of Pas-de-Calais, Oise, Somme, Aisne and Ardennes are added to the ISA calculation for GPs, midwives and gynecologists respectively (Table 1 ). The "average population" columns show that les IRIS neighboring have lower population density than IRIS Nord.

The descriptive statistics of the ISA when offer and demand beyond the study area are included or excluded are presented in Table 2. Mean and standard deviation are slightly below when offer and demand outside are taken into account, whichever health professionals are included. The two-means comparison is only statistically different for ISA gynecologist $(p<0.00)$.

\section{Spatial distribution of ISA at IRIS level}

Spatial distributions of ISA for GPs (a), midwives (b) and gynecologists (c) considered separately, and combined in the composite index (d) when offer and demand beyond the department of Nord are included or not (Fig. 2). The maps show minor changes: ISA distributions in the two cases are fairly similar. Changes appear mainly in those IRIS located close to boundaries.

\section{Accounting for edge effect}

In order to focus on ISA variation when offer and demand beyond the study area were included, we distributed the 1346 IRIS into three classes: improved, unchanged and deteriorated according to simple linear regression results (presented with more detail in "Appendix II").

Figure 3 shows that when accounting for healthcare provider source and patient needs outside the area of Nord the percentage of IRIS having decreased ISA is larger than those with increased ISA (13.15 vs. $5.50 \%$ for GPs; 29.79 vs. $15.68 \%$ for midwives and 30.46 vs. $9.88 \%$ for gynecologists). Many past researches have hypothesized that failure to accounting for edge effect will lead to considerable under-reporting of accessibility to facilities. We obtain the exact opposite findings. The composite ISA which give an overall view of accessibility to various types of health professionals is subject to a slight edge effect (25.33\% deteriorated and $21.55 \%$ improved). Those IRIS too far from boundaries to be affected are colored in grey ("outside service area" in the key).

It can be observed in Fig. 4 that IRIS where GPs ISA changed are mainly located close to the boundaries. Conversely, only 36 IRIS where midwives ISA are not impacted as a result of distance, and 2 IRIS for gynecologists ISA. The white zone does not mean that they are not subject to edge effect, but rather reveal the existence

Table 2 Descriptive statistics of ISA when accounting or not for the edge effect-North department

\begin{tabular}{|c|c|c|c|c|c|c|}
\hline & \multicolumn{3}{|c|}{ When not accounting for the edge effects } & \multicolumn{3}{|c|}{ When accounting edge effects } \\
\hline & $\operatorname{Min}^{¥}$ & Mean (SD*) & $\operatorname{Max}^{\phi}$ & $\operatorname{Min}^{¥}$ & Mean (SD*) & $\operatorname{Max}^{\phi}$ \\
\hline GPS & 1.67 & $93.42(35.74)$ & 245.88 & 1.67 & $92.98(35.17)$ & 245.88 \\
\hline Midwives & 0 & $22.64(11.57)$ & 50.29 & 0 & $21.16(11.06)$ & 49.90 \\
\hline Gynecologists & 0 & $22.47(9.51)$ & 43.76 & 0 & $20.20(8.62)$ & 41.46 \\
\hline Composite index ${ }^{* *}$ & 0.40 & $39.38(14.19)$ & 91.43 & 0.41 & $39.40(13.92)$ & 91.98 \\
\hline
\end{tabular}

ISA GPs is expressed per 100,000 inhabitants, ISA Midwives per 100,000 women inhabitants aged between 15 and 44 and ISA gynecologists per 100,000 women inhabitants

*Standard deviation

**Composite ISA resulting from the principal component analysis

* Minimum

$\$$ Maximum 

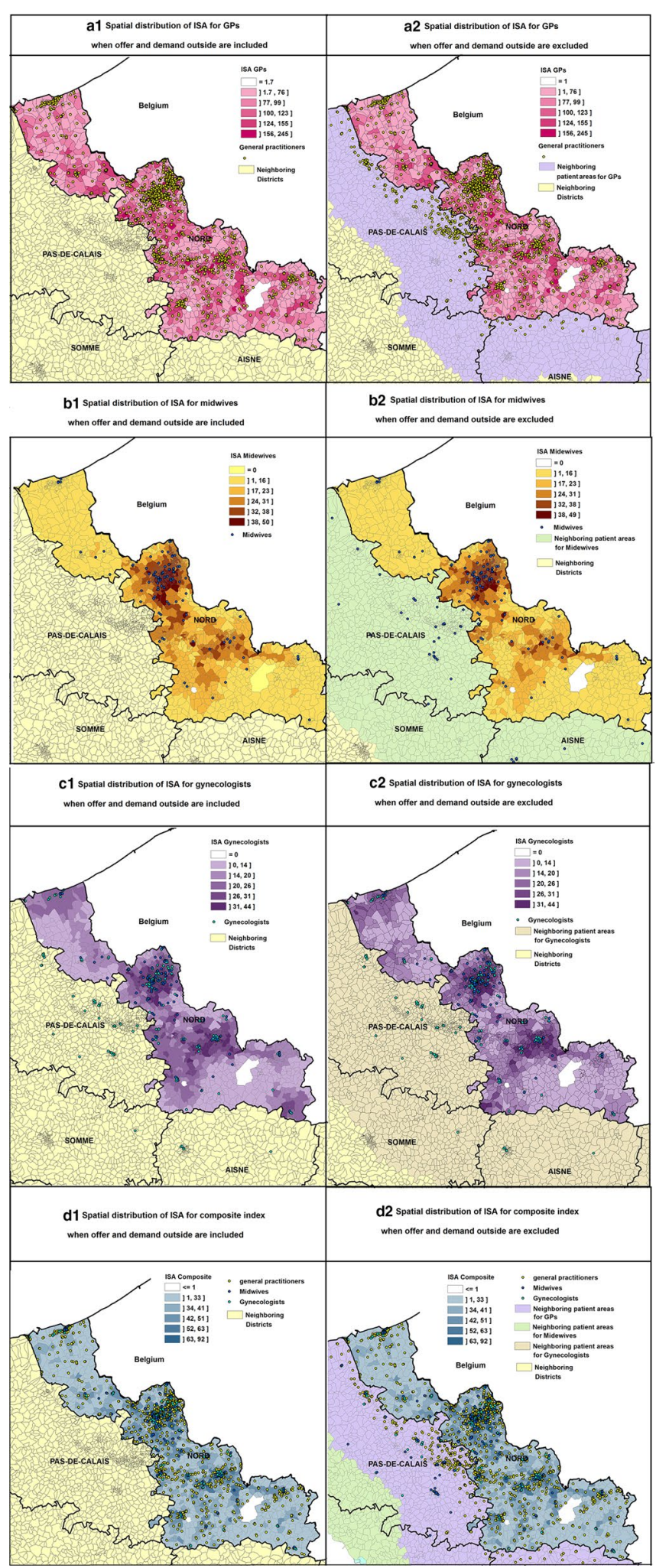

Fig. 2 Spatial distribution of ISA when offer and demand outside are included or excluded. ISA distribution is showed for GPs (a), midwives (b) and gynecologists (c) and combined in the composite index (d). For each map, neighboring departments are colored in yellow and the department of Nord is colored using a graduated approach (according to Jenks' Natural Breaks), showing different ISA scales at IRIS level, expressed per 100,000 inhabitants. The 1362, 2425 and 2583 Neighboring IRIS added to the ISA calculation for GPs, midwives and gynecologists when edge effect included are colored purple, green and khaki respectively 


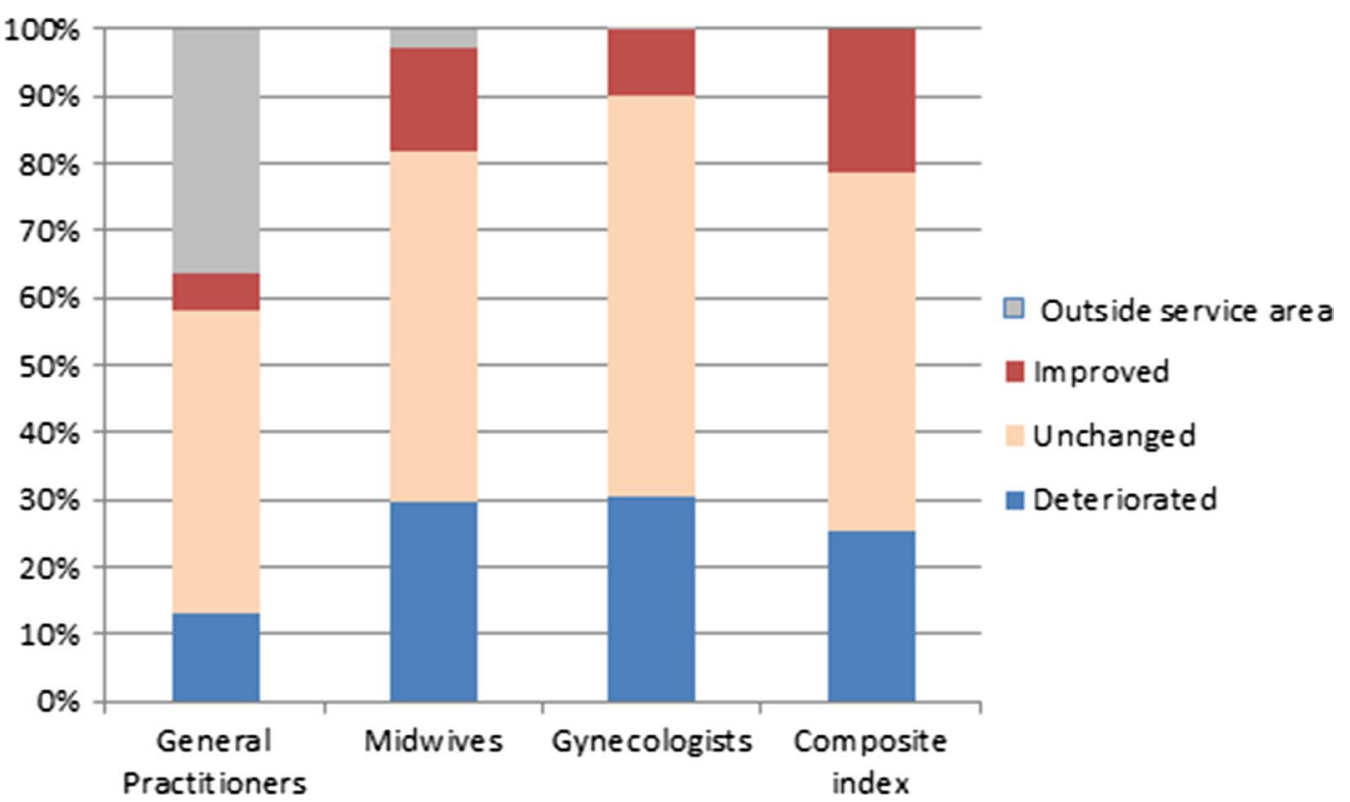

Fig. 3 Percentage of residential IRIS having improved/unchanged/deteriorated accessibility when accounting for edge effect

of a kind of "balance": people from this zone could reach more healthcare professionals beyond the department of Nord but at the same time they must share health resources with residents from neighboring departments. Their accessibility score therefore remains relatively stable.

When focusing on composite ISA, results reveal that all IRIS are subject to edge effect. Most of the IRIS located close to the border and in the agglomeration area (such as Roubaix, Anzin, Maubeuge and Saint-Pol-sur-Mer) saw their ISA improved. However, more IRIS have a deteriorated ISA (25.3\%) than an improved ISA (21.5\%).

\section{Spatial analysis of ISA}

The result of Moran's test for the composite ISA reveal significant spatial autocorrelation $(I=0.73$ when offer and demand beyond the study area are included, and $\mathrm{I}=0.74$ when excluded $-p=0.0001$, pseudo-significance values based on a permutation approach [56]). This means that the IRIS which have a high level of healthcare accessibility are more often located close to other IRIS having a high ISA score in the two cases than they were if this distribution were random.

Figure 5 shows the mapped results of the LISA statistics calculations. According to the results obtained from the LISA statistics, when excluding the offer and demand beyond the boundary, the 1346 IRIS are distributed as follows (Table 3): $287 \mathrm{HH}$-type (high level surrounded by high levels), 273 LL-type (low level surrounded by low levels). Despite some minor differences, we found similar distribution of LISA statistics: 277 HH-type, 264 LL-type.

\section{Comparative analysis of urban and rural ISA variation with edge effect}

Figure 6 shows the ISA variation when accounting for the edge effect and the distribution of urban IRIS and rural (hatched) IRIS. Most IRIS in the department of Nord are urban (1030 urban vs. 336 rural), concentrated around several densely-populated areas close to major cities such as Lille, Roubaix, Tourcoing and Villeneuve d'Ascq (Fig. 6). Using a $10 \mathrm{~km}$ buffer zone around the boundaries, we estimated that 180 rural IRIS (54\% of total rural IRIS) and 304 urban IRIS (just 29\% of total urban IRIS) were near the Nord Pas-de-Calais and the Nord Aisne border.

Figure 7 shows the percentage of urban/rural IRIS variation separately, when offer and demand beyond the boundary were included. Overall, for ISA midwives and gynecologists, there is more variation in rural IRIS: only 16.14 and $26.25 \%$ of rural IRIS remain unchanged for ISA midwives and gynecologists respectively, compared with 48.35 and $62.82 \%$ of urban IRIS. Moreover, a sharp downward trend was observed in the rural zone; about $53.80 \%$ of rural IRIS have a deteriorated ISA midwife and gynecologist value. 


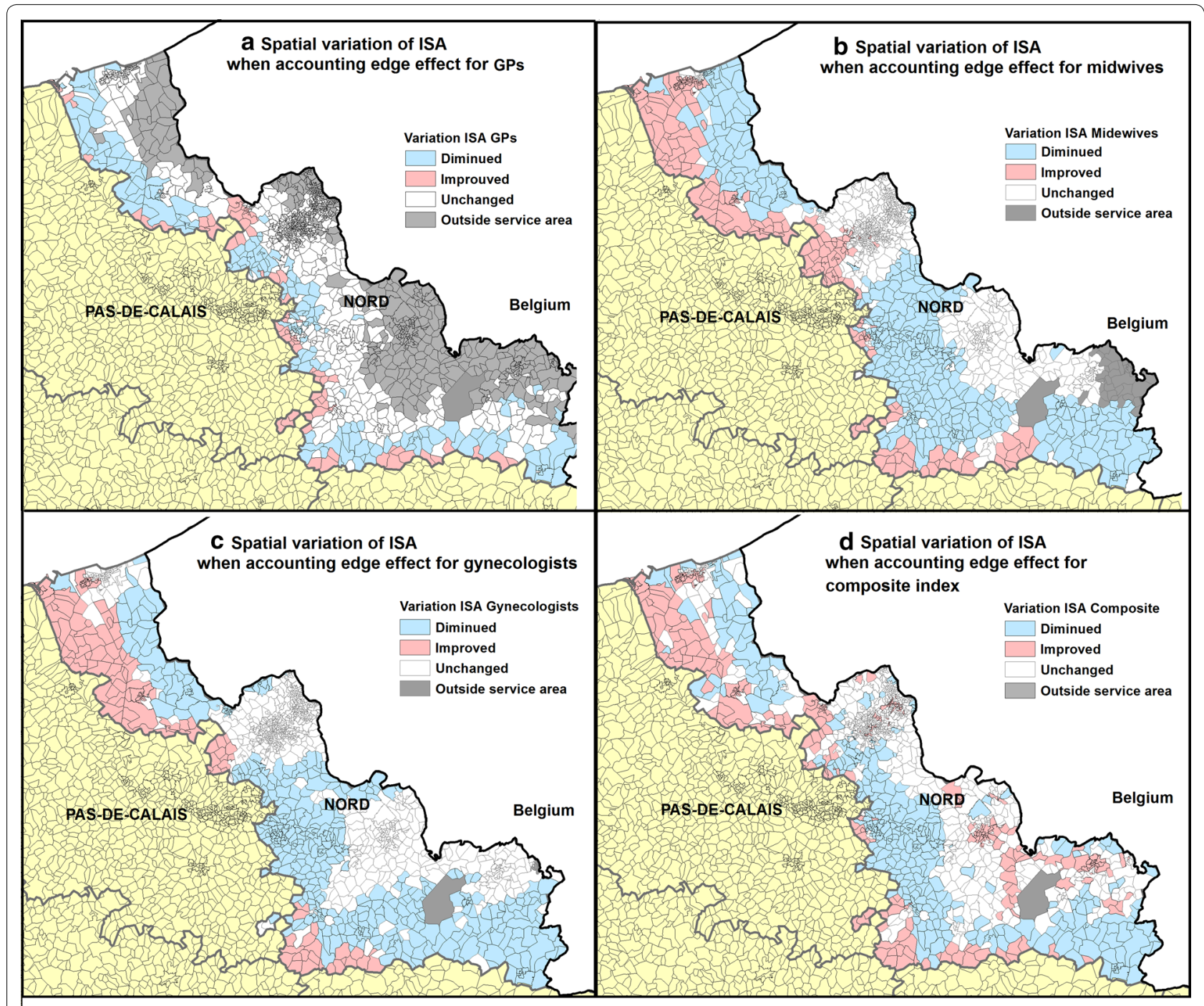

Fig. 4 Spatial variation of ISA when including offer and demand beyond the department of Nord. Variation is displayed for GPS (a), midwives (b) and gynecologists (c) considered separately, along with the composite index (d). All IRIS that are too far from boundaries (by car travel time) to be affected are shaded grey

\section{Spatial variation of ISA according to socioeconomic distress level}

The strength of the associations between the socioeconomic distress variable and composite ISA when offer and demand beyond the boundary were included or exclude are quite similar (Table 4): the association between socioeconomic factor and accessibility is therefore not impacted when offer and demand beyond the boundary Included. All the associations are positive and statistically significant $(p<0.0001)$ with the exception of the level of education; the association with women's unemployment is close to reaching statistical significance. Population residing in the more deprived neighborhoods have the highest level of accessibility to healthcare providers, suggesting that there is no systematic absence of healthcare providers in impoverished areas.

\section{Discussion}

This work highlights the impacts of edge effect on spatial modelling of accessibility to healthcare professionals; this has been a matter of some concern to spatial analysts. Edge effect is one of the most commonly mentioned problems in studies dealing with spatial accessibility. We were interested in exploring the role of edge effect, to determine whether or not it has a relevant impact on healthcare provider accessibility in the department of Nord, using the "Index of Spatial Accessibility" previously 


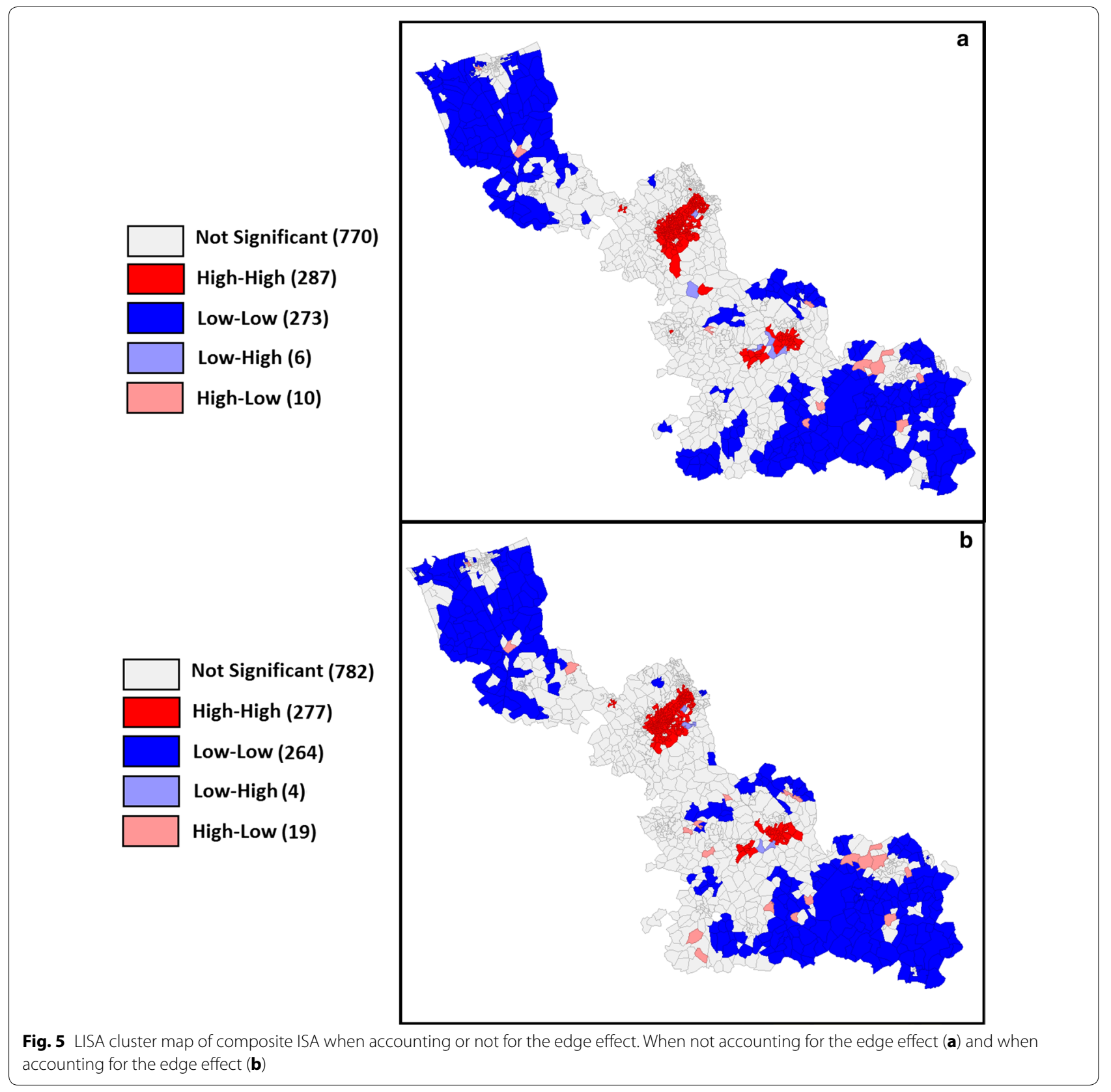

developed by our team [44]. Our study has shown that it is difficult to reach a general conclusion. Firstly, in many published studies, authors have argued that accessibility to facilities (including healthcare providers) will lead to considerable biases [34-37], even under-reporting [17, $28,29,31,43]$ when not accounting for the edge effect. Our work has revealed that on average, the Index of Spatial Accessibility is only slightly lower with edge effect accounted, than without. In addition, when accounting for the edge effect, our study suggests that more IRIS see their value reduced than see it improved. Indeed, when spatial analyses are not limited within a finite region, not only are facilities beyond the border disregarded, but the fact that patients from the neighboring area are also able to overcome geographical boundaries and consult a healthcare professional within the department of Nord is also ignored.

More specifically, the role of edge effect is largely linked to the method used to estimate accessibility. A range of methods exists for measurement of spatial accessibility to healthcare professionals-including Physician Population Ratio, distance/time (Euclidean, Manhattan, or network) 
Table 3 Descriptive statistics of composite ISA in the IRIS types obtained by LISA statistics

\begin{tabular}{|c|c|c|c|c|c|c|}
\hline LISA statistic level types & $\mathrm{HH}$ & LL & LH & $\mathrm{HL}$ & NS & Total \\
\hline Number of IRIS when accounting for the edge effect & 287 & 273 & 6 & 10 & 770 & 1346 \\
\hline$\%$ & $21.3 \%$ & $20.3 \%$ & $0.4 \%$ & $0.7 \%$ & $57.2 \%$ & \\
\hline \multicolumn{7}{|l|}{ ISA composite } \\
\hline Minimum & 40.1 & 0.4 & 33.8 & 36.3 & 7.0 & \\
\hline Mean & 57.0 & 24.3 & 36.3 & 45.1 & 38.1 & \\
\hline Standard deviation & 8.7 & 7.9 & 2.0 & 5.2 & 10.1 & \\
\hline Maximum & 91.4 & 39.8 & 38.8 & 58.8 & 77.8 & \\
\hline Number of IRIS when not accounting for the edge effect & 277 & 264 & 4 & 19 & 782 & 1346 \\
\hline$\%$ & $20.6 \%$ & $19.6 \%$ & $0.3 \%$ & $1.4 \%$ & $58.1 \%$ & \\
\hline \multicolumn{7}{|l|}{ ISA composite } \\
\hline Minimum & 41.3 & 0.4 & 6 & 39.7 & 7.2 & \\
\hline Mean & 57.2 & 24.6 & 33.5 & 45.2 & 38.2 & \\
\hline Standard deviation & 8.7 & 7.7 & 36.3 & 4.2 & 9.7 & \\
\hline Maximum & 92.0 & 39.2 & 2.6 & 54.4 & 76.7 & \\
\hline
\end{tabular}

Results when accounting or not for the edge effects are shown separately

to the nearest healthcare professional, average distance/ time to a certain number of healthcare professionals, cumulative opportunity (which counts the number of opportunities that can be reached within a travel time) $[22,54]$ and the gravity model $[23,24]$. When the accessibility indicator is based on availability or proximity (such as distance/time or cumulative opportunity) taking facilities beyond the border into account can improve the accessibility score. However, when the availability measure is weighted by population size (as our ISA indicator is), so that the volume of services available (relative to the population's size and the proximity of services available relative to the location of the population) is taken into account, it is also important to consider demand from the population on the other side of the border. The population living either side of the study border must share the healthcare supply. As a result, the impact of edge effect on this type of accessibility indicator is more subtle; variation occurs in a balanced way, and should not be subject to arbitrary conclusions.

Secondly, our study shows that depending on health professional type, edge effect impact may vary considerably. We found that changes to GPs ISA are mainly in those IRIS located close to the boundaries. One explanation is that the "patient area" of GPs is limited ( $\leq 15 \mathrm{~min}$ ) [44, 54]. Moreover, GP numbers are much higher than specialist doctor numbers, leading to more homogenous distribution. Consequently, supply and demand beyond the border will not have a very significant impact. Conversely, midwife and gynecologist numbers are very limited. People may be willing to travel further/longer to access a specialist doctor. This is why almost all IRIS are impacted by distance. Yet variations in ISA values are minor, because of the balance' of edge effects.

Healthcare accessibility is especially vital for rural populations; a matter that has long been of concern to community and health planners [17, 31-33]. Typically, these populations experience restricted access to healthcare and other resources due to the spatial inequality of living in rural or impoverished areas. ISA comparisons between urban and rural zones reveal a greater variability within the group of rural IRIS than within the group of urban IRIS. This finding may be partially explained by the spatial distribution of the rural IRIS located close to the border of the study area: $54 \%$ of rural IRIS are located within ten kilometers (as the crow flies) from the frontier (as against only 29\% of urban IRIS). However, the fact that a steep downward trend was observed in the rural zone when offer and demand beyond the boundary were included is both unexpected and related specifically to the distribution of healthcare providers and consumers in the department of Nord and its neighboring areas. This result should therefore be analyzed and interpreted with caution, since it is study-area dependent. One of the explanations is that the physicians' density of district Nord (436.2 per 100,000 inhabitants) is greater than its neighboring districts: 307.2 for Pas-de-Calais, 271.1 for Oise, 401.1 for Somme, 280.2 for Aisne and 288.5 for Ardennes [60]. On the other hand, in most cities in the Nord department, when edge effect is corrected, the ISA score is mainly classified as 'unchanged'-thanks to wellbalanced offer and demand.

We found a positive correlation between socioeconomic distress levels and composite ISA. This finding suggests that areas of high socioeconomic distress tended 


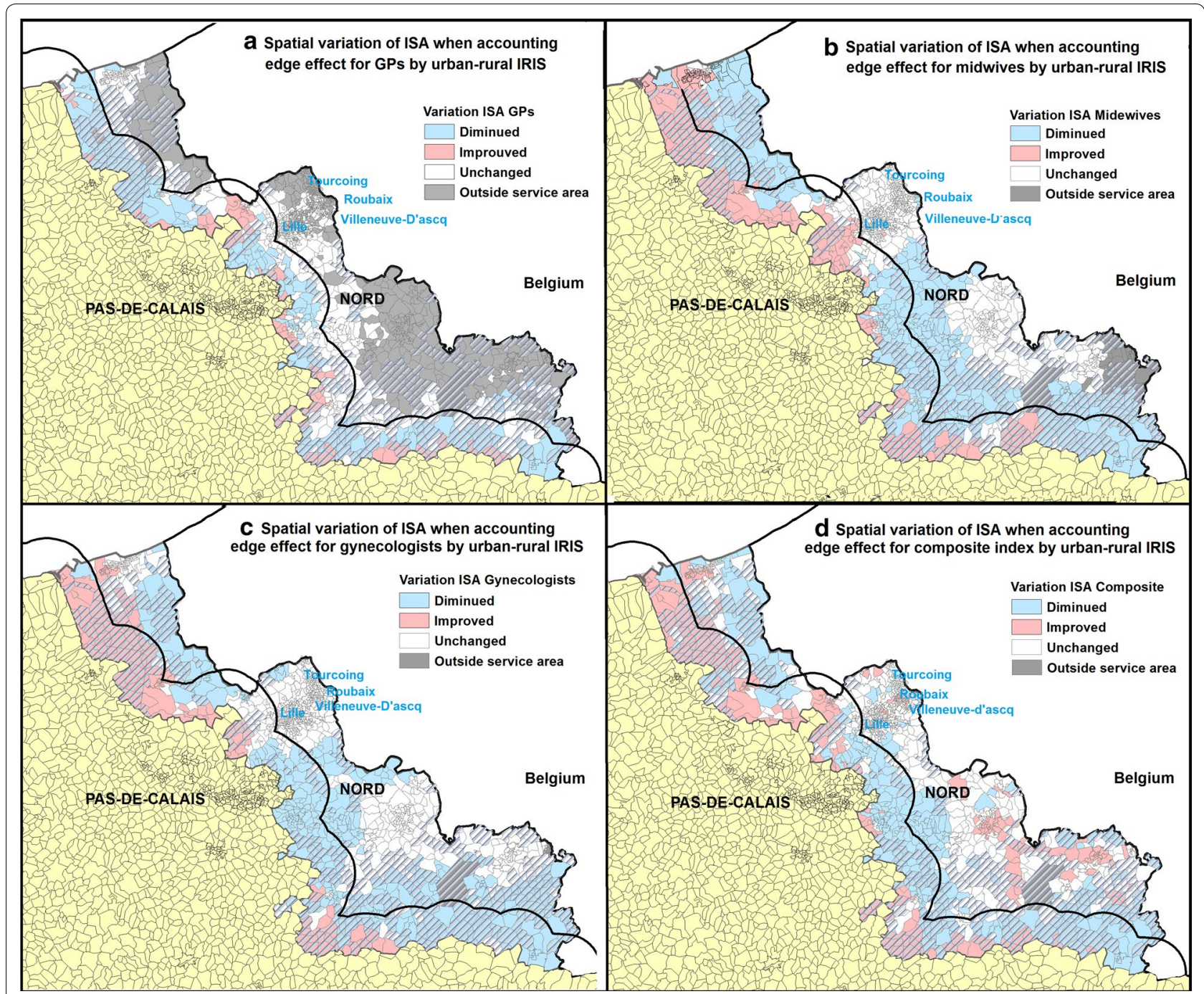

Fig. 6 Spatial variation of ISA and the distribution of urban/rural IRIS. ISA variation is showed for GPs (a), midwives (b) and gynecologists (c) and the composite index (d). Rural IRIS are hatched. We created a 10KM buffer zone around the boundaries

to have better access than low socioeconomic distress areas. This result is not surprising, given the spatial planning of the Nord department: lower-income residents are more likely to live in urban areas in which social housing and services are concentrated. This significant association is quite similar to the result when offer and demand beyond the boundary were excluded: inclusion of offer and demand beyond the boundary did not impact the relationship between distress levels and composite ISA within our study area. These findings tend to demonstrate that the impact of edge effect is dependent on both the spatial distribution of healthcare providers and territorial organization.

Our study aims to provide additional evidence to the existing scientific literature in the field of spatial accessibility to healthcare by carrying out a detailed examination of the impact of edge effect. To our knowledge, this is the first work assessing edge effect based on algorithm E2SFCA. No research has explicitly demonstrated access differences when outside healthcare sources and patient demand are excluded or included. This study highlights the fact that there is a inaccuracy in hypothesizing that accessibility will be considerably and systematically under-reported where external healthcare providers are excluded. Indeed, our study found IRIS in which the ISA was reduced when offer and demand beyond the boundary were included. The result of this study will be useful to both health resource planners and other researchers in the public health field.

Several limitations of this study should be addressed here. Despite its relative popularity of algorithm, the E2SFCA method remained highly debated. The choice 


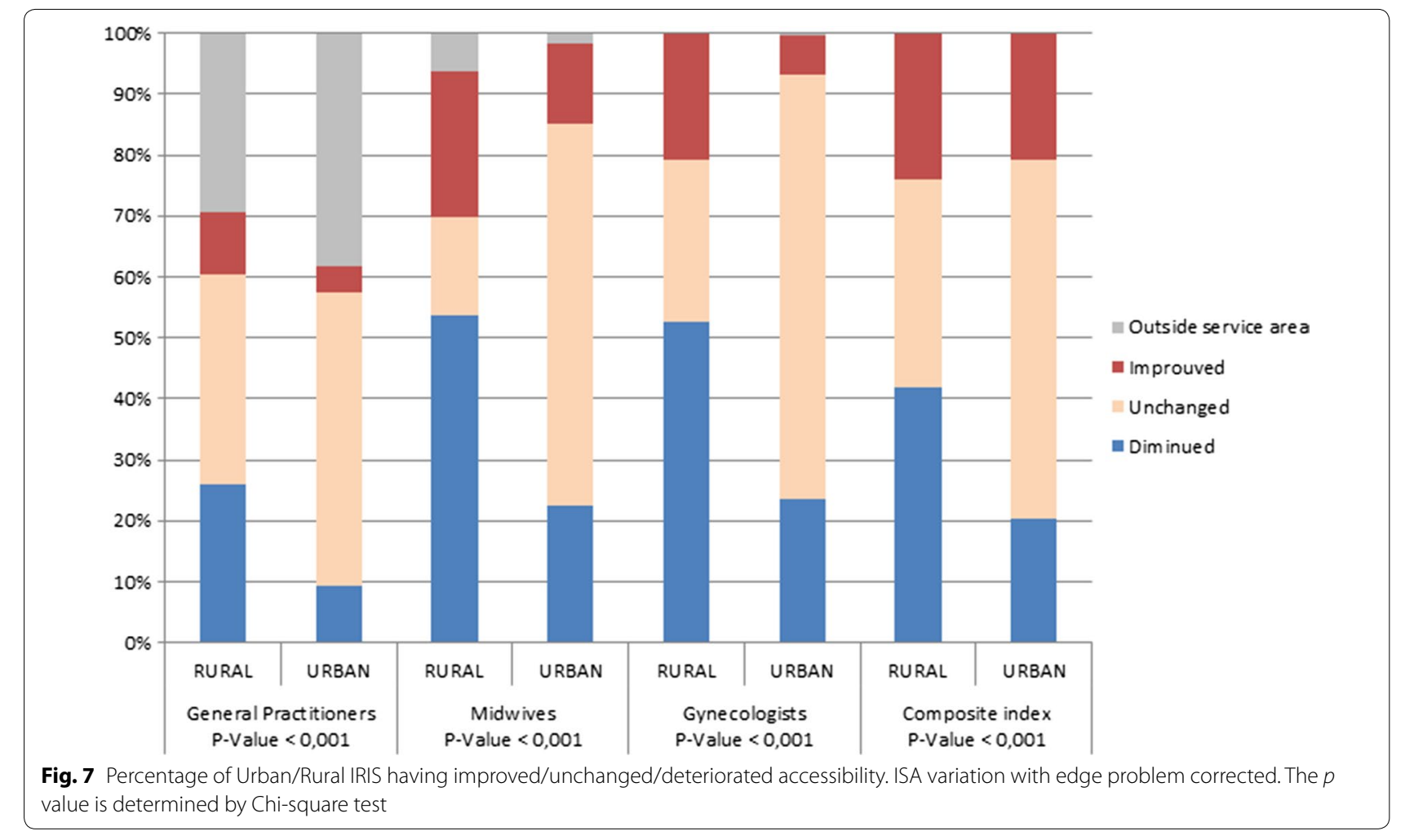

Table 4 Simple linear regression between Socioeconomic variables and composite ISA when accounting or not edge effect

\begin{tabular}{|c|c|c|c|c|c|c|}
\hline & \multicolumn{3}{|c|}{$\begin{array}{l}\text { ISA composite when not accounting edge } \\
\text { effects }\end{array}$} & \multicolumn{3}{|c|}{$\begin{array}{l}\text { ISA composite when accounting edge } \\
\text { effects }\end{array}$} \\
\hline & $\beta$ & $\mathrm{Cl} 95 \% *$ & $p$ value & $\beta$ & $\mathrm{Cl} 95 \% *$ & $p$ value \\
\hline Single parent families & 81.3 & {$[72.8,89.9]$} & $<0.0001$ & 79.7 & {$[71.3,88.1]$} & $<0.0001$ \\
\hline Non-homeowner & 26.5 & {$[23.6,29.4]$} & $<0.0001$ & 26.2 & {$[23.4,29.0]$} & $<0.0001$ \\
\hline Insecure employment & 24.9 & {$[13.1,36.6]$} & $<0.0001$ & 27.0 & {$[15.5,38.5]$} & $<0.0001$ \\
\hline Women's unemployment rate & 8.7 & {$[-.3,17.8]$} & 0.058 & 9.3 & {$[.5,18.2]$} & 0.04 \\
\hline Low level of educational attainment among women & 5.0 & {$[-3.3,13.4]$} & NS 0.24 & 5.9 & {$[-2.3,14.0]$} & NS 0.16 \\
\hline
\end{tabular}

${ }^{*}$ Confidence interval at $95 \%$

of the best decay function or the right size for catchment areas needs rigorous modeling to derive the best fitting parameters [61]. In the absence of appropriate empirical evidence, it was necessary to make a number of estimations during the definition of distance-decay function and the threshold for healthcare professionals other than general practitioners.

Another limitation is aggregation error, which arises when measuring distance from aggregated areal units to facilities, and results from the use of a single point as a proxy for the locations of individuals within the area units [5]. We have attempted to reduce aggregation error by considering the spatial distribution of the living building, since it better reflects the spatial distribution of individuals $[5,62]$.

In this study, we were not interested in the interaction across the border between France and Belgium. Even though the European Health Insurance Card (EHIC) gives the right to access state-provided healthcare during a temporary stay in another European Economic Area, a pregnant woman have make a specific request. This request must then be accepted to be able to benefit from health care during the pregnancy and to avoid advancing their own funds to cover expenses, which do add an extra layer of administrative complexity. We assumed therefore that the offer and demand 
of pregnancy-related healthcare across this border is limited.

In addition, it is also worth noting that (as in many other studies dealing with spatial accessibility) our method concerns only potential spatial accessibility, rather than revealed access (actual utilization of healthcare). Only complex and expensive investigations would be capable of providing the complementary information that would allow us to distinguish the difference between spatial and real access and use of healthcare services. Finally, our study addresses difficulties arising from the use of a large amount of data and distance calculation prior to application of the algorithm, which is time consuming and calls for technical know-how. However, this is the price to be paid for a more accurate indicator.

\section{Conclusion}

Access to healthcare services will continue to be one of the most important public health preoccupations, especially in the context of the increase of social health inequalities worldwide. Our study gave a real illustration of what could be the impact of edge effect in healthcare access in a French context. Our results did not support the "under-report" hypothesis discussed in many published studies. On the whole, our research has revealed only minor average value variations of ISA as a result of including interactions across the border. One explanation is that a kind of balance patient and healthcare professionals when considering neighboring department. However, it is not possible to set up general statement because intensity of impact varies according to healthcare provider type, urbanization level and territorial organization; in addition, we also know that the methodology implemented to measure the healthcare access combined with the size of the spatial unit may influence how the edge effect could impact the measure of healthcare accessibility. For these reason, we plan to carry out this study for another study area with a different territorial organization, to compare ISA variation in two cases in order to get a conclusion more general, at the France scale. Additional researches are required in different countries in order to improve our level of understanding about the influence of the edge effect on the accessibility to healthcare. Following the same methodology to measure the accessibility to healthcare, these different studies will help to distinguish what findings are specific to the characteristics and organization of the country and what findings are common to the different counties. It constitute a promising direction to determine more precisely healthcare shortage areas and then to fight against social health inequalities.
In conclusion, edge effect must be considered on a case-by-case basis, because it relies on choice of indicator, spatial distribution of facilities and urban organization of the territory studied.

This study represents an important step. It will serve not only to assist current researchers by identifying the common methodological hypothesis bias of edge effect in spatial accessibility studies, but will also be helpful to planners and other researchers in the public health field. This paper has presented high-quality geographic data and advanced GIS techniques. In order to examine whether the results are generalizable to different spatial scales and distribution, we hope to contribute to other areas of study in the near future.

\section{Abbreviations}

E2FCA: enhanced two-step floating catchment area; INSEE: National Institute of Statistics and Economic Studies; ISA: spatial accessibility index; IRIS: L'Îlot Regroupé pour des Indicateurs Statistiques.

\section{Authors' contributions}

Work presented here was conceived, carried out and analyzed by FG, SD and WK. MS and NL gave important suggestions and supervised the study. All authors read and approved the final manuscript.

\section{Author details}

${ }^{1}$ EHESP Rennes, Sorbonne Paris Cité, Paris, France. ${ }^{2}$ LIVE UMR 7362 CNRS (Laboratoire Image Ville Environnement), University of Strasbourg, 6700 Strasbourg, France. ${ }^{3}$ L'équipe REPERES, Recherche en Pharmaco-épidémiologie et recours aux soins, UPRES EA-7449, Rennes, France. ${ }^{4}$ IRD, UMR_D 190 "Emergence des Pathologies Virales" (IRD French Institute of Research for Development, Aix-Marseille University, EHESP French School of Public Health), Marseille, France. ${ }^{5}$ Department of Quantitative Methods for Public Health, EHESP School of Public Health, Avenue du Professeur Léon Bernard, 35043 Rennes, France. ${ }^{6}$ Department of Social Epidemiology, Sorbonne Universités, UPMC Univ Paris 06, INSERM, Institut Pierre Louis d'Epidémiologie et de Santé Publique (UMRS 1136), Paris, France.

\section{Acknowledgements}

This research is supported by EHESP Rennes, Sorbonne Paris Cité and Institut de recherche sur la santé l'environnement et le travail. Points of view or opinions in this article are those of the authors and do not necessarily represent the official position or policies of the EHESP Rennes, Sorbonne Paris Cité and IRSET.

\section{Competing interests}

The authors declare that they have no competing interests.

\section{Availability of data and materials}

All data generated or analysed during this study are included in this published article. If readers need supplementary information, they can contact me (fei. gao@ehesp.fr).

\section{Consent for publication}

Not applicable.

Ethics approval and consent to participate Not applicable.

Funding

Not applicable. 


\section{Appendix I}

\begin{tabular}{|c|c|}
\hline Socioeconomic variables & Definition \\
\hline Low level of educational attainm & $\begin{array}{l}\text { Proportion of women aged } 25 \text { and } \\
\text { over not having graduated from } \\
\text { high school }\end{array}$ \\
\hline Women's unemployment rate & $\begin{array}{l}\text { Proportion of unemployed women } \\
\text { eligible to work }\end{array}$ \\
\hline Single parent families & $\begin{array}{l}\text { Proportion of all households with } \\
\text { children headed by lone parents }\end{array}$ \\
\hline Non-homeowner & $\begin{array}{l}\text { Proportion of all households not } \\
\text { owning their main residence }\end{array}$ \\
\hline Insecure employment situation & $\begin{array}{l}\text { Proportion of those on short-term } \\
\text { or temporary contracts, in state- } \\
\text { funded posts, or apprenticeship/ } \\
\text { internship }\end{array}$ \\
\hline
\end{tabular}

\section{Appendix II}

\section{See Fig. 8.}

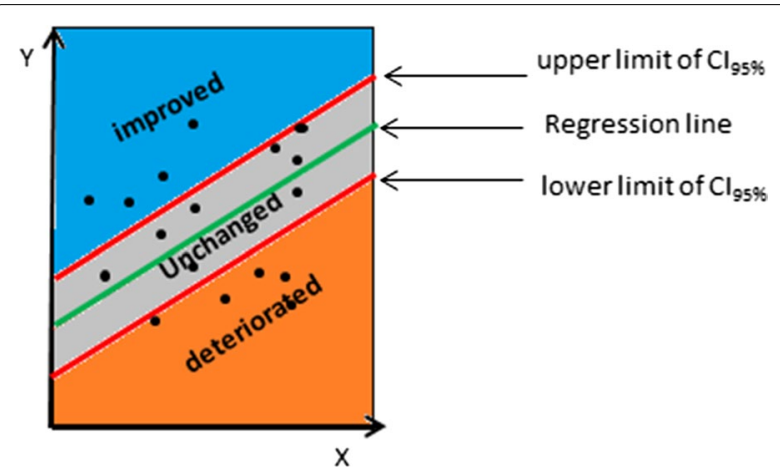

Fig. $8 X$ represents ISA when not accounting for edge effect; $Y$ represents ISA when accounting for the edge effect. Class of "unchanged" in grey color: the change between $X$ and $Y$ is in the average; it is points around the green regression line within the $95 \%$ confidence interval (red lines); Class deteriorated in orange color: Points placed below the lower limit of the $95 \%$ confidence interval which signifies that these IRIS have a larger reduction than the average (the reverse for "improved" in blue color)

\section{Publisher's Note}

Springer Nature remains neutral with regard to jurisdictional claims in published maps and institutional affiliations.

Received: 2 March 2017 Accepted: 26 November 2017 Published online: 11 December 2017

\section{References}

1. Sasaki S, Comber AJ, Suzuki H, Brunsdon C. Using genetic algorithms to optimise current and future health planning-the example of ambulance locations. Int J Health Geogr. 2010;9:4. https://doi. org/10.1186/1476-072X-9-4
2. Walsh SJ, Page PH, Gesler WM. Normative models and healthcare planning: network-based simulations within a geographic information system environment. Health Serv Res. 1997;32:243-60.

3. Patel $A B$, Waters NM, Ghali WA. Determining geographic areas and populations with timely access to cardiac catheterization facilities for acute myocardial infarction care in Alberta, Canada. Int J Health Geogr. 2007;6:47. https://doi.org/10.1186/1476-072X-6-47.

4. Parker EB, Campbell JL. Measuring access to primary medical care: some examples of the use of geographical information systems. Health Place. 1998;4:83-193

5. Hewko J, Smoyer-Tomic KE, Hodgson MJ. Measuring neighbourhood spatial accessibility to urban amenities: does aggregation error matter? Environ Plan A. 2002;34(7):1185-206.

6. Talen E. Visualizing fairness: equity maps for planners. J Am Plan Assoc. 1998;64(1):22-38.

7. Talen E, Anselin L. Assessing spatial equity: an evaluation of measures of accessibility to public playgrounds. Environ Plan A. 1998;30(4):595-613.

8. Lawrence D, Kisely S. Inequalities in healthcare provision for people with severe mental illness. J Psychopharmacol. 2010;24(Suppl 4):61-8. https:// doi.org/10.1177/1359786810382058.

9. Charreire $\mathrm{H}, \mathrm{Combier} \mathrm{E.} \mathrm{Poor} \mathrm{prenatal} \mathrm{care} \mathrm{in} \mathrm{an} \mathrm{urban} \mathrm{area:} \mathrm{a} \mathrm{geographic}$ analysis. Health Place. 2009;15(2):412-9.

10. Smoyer-Tomic KE, Spence JC, Raine KD, Amrhein C, Cameron N, Yasenovskiy V, Cutumisu N, Hemphill E, Healy J. The association between neighborhood socioeconomic status and exposure to supermarkets and fast food outlets. Health Place. 2008;14:740-54. https://doi.org/10.1016/j. healthplace.2007.12.001.

11. Ball K, Timperio A, Crawford D. Neighbourhood socioeconomic inequalities in food access and affordability. Health Place. 2009;15:578-85. https:// doi.org/10.1016/j.healthplace.2008.09.010.

12. Galvez MP, Hong L, Choi E, Liao L, Godbold J, Brenner B. Childhood obesity and neighborhood food-store availability in an inner-city community. Acad Pediatr. 2009;9:339-43. https://doi.org/10.1016/j.acap.2009.05.003.

13. Spence JC, Cutumisu N, Edwards J, Raine KD, Smoyer-Tomic K. Relation between local food environments and obesity among adults. BMC Public Health. 2009;9:192. https://doi.org/10.1186/1471-2458-9-192.

14. Macdonald L, Ellaway A, Macintyre S. The food retail environment and area deprivation in Glasgow City, UK. Int J Behav Nutr Phys Act. 2009;6:52. https://doi.org/10.1186/1479-5868-6-52.

15. Feng J, Glass TA, Curriero FC, Stewart WF, Schwartz BS. The built environment and obesity: a systematic review of the epidemiologic evidence. Health Place. 2010;16:175-90. https://doi.org/10.1016/j. healthplace.2009.09.008.

16. Hu R, Dong S, Zhao Y, Hu H, Li Z. Assessing potential spatial accessibility of health services in rural China: a case study of Donghai County. Int J Equity Health. 2013;12:35. https://doi.org/10.1186/1475-9276-12-35.

17. Wang F, Luo W. Assessing spatial and nonspatial factors for healthcare access: towards an integrated approach to defining health professional shortage areas. Health Place. 2005;11(2):131-46. https://doi.org/10.1016/j. healthplace.2004.02.003.

18. Wang F. Quantitative methods and applications in GIS. Boca Raton: Taylor \& Francis Group; 2005.

19. Matsumoto M, Inoue K, Noguchi S, Toyokawa S, Eiji K. Community characteristics that attract physicians in Japan: a cross-sectional analysis of community demographic and economic factors. Human Resour Health. 2009;7:12.

20. Ranga V, Panda P. Geospat Spatial access to inpatient health care in northern rural India. Health. 2014;8(2):545-56.

21. Talen E. Neighborhoods as service providers: a methodology for evaluating pedestrian access. Environ Plan B. 2003;30:181-200. https://doi. org/10.1068/b12977.

22. Apparicio P, Abdelmajid M, Riva M, Shearmur R. Comparing alternative approaches to measuring the geographical accessibility of urban health services: distance types and aggregation-error issues. Int J Health Geogr. 2008;7:7. https://doi.org/10.1186/1476-072X-7-7.

23. Guagliardo MF. Spatial accessibility of primary care: concepts, methods and challenges. Int J Health Geogr. 2004;3:3. 
24. Martin D, Williams HCWL. Market-area analysis and accessibility to primary health-care centres. Environ Plan. 1992;24:1009-19.

25. Bamford EJ, Dunne L, Taylor DS, Symon BG, Hugo GJ, Wilkinson D. Accessibility to general practitioners in rural South Australia. Med J Aust. 1999:171(11-12):614-6.

26. Apparicio P, Cloutier M-S, Shearmur R. The case of Montréal's missing food deserts: evaluation of accessibility to food supermarkets. Int J Health Geogr. 2007;6(1):4.

27. Luo W, Qi Y. An enhanced two-step floating catchment area (E2SFCA) method for measuring spatial accessibility to primary care physicians. Health Place. 2011:17(1):394.

28. Sadler RC, Gilliland JA, Arku G. An application of the edge effect in measuring accessibility to multiple food retailer types in Southwestern Ontario, Canada. Int J Health Geogr. 2010;10:34.

29. Salze P, Banos A, Oppert J-M, Charreire H, Casey R, Simon C, Chaix B, Badariotti D, Weber C. Estimating spatial accessibility to facilities on the regional scale: an extended commuting-based interaction potential model. Int J Health Geogr. 2011. https://doi.org/10.1186/1476-072X-10-2.

30. Vidal Rodeiro CL, Lawson AB. An evaluation of the edge effects in disease map modelling. J Comput Stat Data Anal. 2005;49:45-62.

31. Sharkey JR, Horel S. Neighborhood socioeconomic deprivation and minority composition are associated with better potential spatial access to the ground-truthed food environment in a large rural area. J Nutr. 2008;138(3):620-7.

32. Wan N, Zhan FB, Zou B, Chow E. A relative spatial access assessment approach for analyzing potential spatial access to colorectal cancer services in Texas. Appl Geogr. 2012;32:291-9. https://doi.org/10.1016/j. apgeog.2011.05.001.

33. Ngui AN, Apparicio P. Optimizing the two-step floating catchment area method for measuring spatial accessibility to medical clinics in Montreal. BMC Health Serv Res. 2011;11:166. https://doi. org/10.1186/1472-6963-11-166.

34. Fortney PD, Rost J, Warren J. Comparing alternative methods of measuring geographic access to health services. Health Serv Outcomes Res Methodol. 2000;1 (2):173-84.

35. Van Meter EM, Lawson AB, Colabianchi N, Nichols M, Hibbert J, Porter DE, Liese AD. An evaluation of edge effects in nutritional accessibility and availability measures: a simulation study. Int J Health Geogr. 2010;9:40. https://doi.org/10.1186/1476-072X-9-40.

36. Bissonnette L, Wilson K, Bell S, Shah TI. Neighbourhoods and potential access to health care: the role of spatial and aspatial factors. Health Place. 2012;18(4):841-53. https://doi.org/10.1016/j.healthplace.2012.03.007.

37. Donohoe J, Marshall V, Tan X, Camacho FT, Anderson R, Balkrishnan R. Evaluating and comparing methods for measuring spatial access to mammography centers in Appalachia (Re-Revised). Health Serv Outcomes Res Methodol. 2016;16(1):22-40.

38. Jordan H, Roderick P, Martin D, Barnett S. Distance, rurality and the need for care: access to health services in South West England. Int J Health Geogr. 2004;3:21. https://doi.org/10.1186/1476-072X-3-21.

39. Luo J, Tian LL, Luo L, Yi H, Wang FH. Two-step optimization for spatial accessibility improvement: a case study of health care planning in rural China. BioMed Res Int. 2017. https://doi.org/10.1155/2017/2094654.

40. Fortney J, Rost K, Warren J. Health services \& outcomes research. Methodology. 2000;1:173. https://doi.org/10.1023/A:1012545106828.

41. Pipley BD. Spatial statistics. New York: Wiley; 1981.

42. Iredale R, Jones L, Gray J, Deaville J. 'The edge effect': an exploratory study of some factors affecting referrals to cancer genetic services in rural Wales. Health Place. 2005;1 1(3):197-204. https://doi.org/10.1016/j. healthplace.2004.06.005.

43. Zhang XY, Lu H, Holt JB. Modeling spatial accessibility to parks: a national study. Int J Health Geogr. 2011;10:31. https://doi. org/10.1186/1476-072X-10-31.
44. Gao F, Kihal W, Le Meur N, Souris M, Deguen S. Assessment of the spatial accessibility to health professionals at French census block level. Int J Equity Health. 2016;15(1):125. https://doi.org/10.1186/s12939-016-0411-z.

45. Jin C, Cheng JQ, Lu YQ, Huang ZF, Cao FD. Spatial inequity in access to healthcare facilities at a county level in a developing country: a case study of Deqing County, Zhejiang, China. Int J Equity Health. 2015;14:67. https://doi.org/10.1186/s12939-015-0195-6.

46. Zhou Z, Su Y, Gao J, Campbell B, Zhu Z, Xu L, Zhang Y. Assessing equity of healthcare utilization in rural China: results from nationally representative. Int J Equity Health. 2013;12:34. https://doi.org/10.1186/1475-9276-12-34.

47. McGrail MR, Humphreys JS. Measuring spatial accessibility to primary care in rural areas: improving the effectiveness of the two-step floating catchment area method. Appl Geogr. 2009;29(4):533-41.

48. Strasser R. Rural health around the world: challenges and solutions. Fam Pract. 2003;20(4):457-63. https://doi.org/10.1093/fampra/cmg422.

49. Institut national de la statistique et des études économiques. http:// www.insee.fr/fr/. Accessed 2 May 2014.

50. Lalloué B, Monnez JM, Padilla C, Kihal W, Le Meur N, Zmirou-Navier D, Deguen S. A statistical procedure to create a neighborhood socioeconomic index for health inequalities analysis. Int J Equity Health. 2013;12:21. https://doi.org/10.1186/1475-9276-12-21.

51. French health insurance. http://annuairesante.ameli.fr/. Accessed $12 \mathrm{Mar}$ 2014.

52. Institut national de l'information géographique et forestière: http://www. ign.fr/.

53. Zdeb M. Driving distances and times using $S A S^{\circledR}$ and Google Maps. SAS Global Forum 2010

54. Barlet M, Coldefy M, Collin C, Lucas-Gabrielli V. L'Accessibilité potentielle localisée (APL): une nouvelle mesure de l'accessibilité aux médecins généralistes libéraux. Institut de recherche et documentation en économie de la santé. Question d'économie de la santé n 174; 2012.

55. McGrail MR. Spatial accessibility of primary health care utilising the two step floating catchment area method: an assessment of recent improvements. Int. J. Popul Geogr. 2012. https://doi. org/10.1186/1476-072X-11-50.

56. Griffith DA. What is spatial autocorrelation? L'Espace Géographique. 1992;21:265-80.

57. Anselin L. Local indicator of spatial association-LISA. Geogr Anal. 1995;27:93-115. https://doi.org/10.1111/j.1538-4632.1995.tb00338.x.

58. Jacquez GM, Greiling DA. Local clustering in breast, lung and colorectal cancer in Long Island, New York. Int J Health Geogr. 2003;2:3. https://doi. org/10.1186/1476-072X-2-3.

59. Talen E. Neighborhoods as service providers: a methodology for evaluating pedestrian access. Environ Plann B. 2003;30:181-200. https://doi. org/10.1068/b12977.

60. https://demographie.medecin.fr/\#l=fr; $v=$ map2. Accessed June 2017.

61. Wang F. Measurement, optimization, and impact of health care accessibility: a methodological review. Ann Assoc Am Geogr Assoc Am Geogr. 2012;102(5):1104-12. https://doi.org/10.1080/00045608.2012.657146.

62. Zhao P, Batta R. Analysis of centroid aggregation for the Euclidean distance p-median problem. Eur J Oper Res. 1999;113(1):147-68. https://doi. org/10.1016/50377-2217(98)00010-1.

\section{Submit your next manuscript to BioMed Central and we will help you at every step:}

- We accept pre-submission inquiries

- Our selector tool helps you to find the most relevant journal

- We provide round the clock customer support

- Convenient online submission

- Thorough peer review

- Inclusion in PubMed and all major indexing services

- Maximum visibility for your research

Submit your manuscript at www.biomedcentral.com/submit 